\title{
Banana Bark as A Part of Acoustic Design Unit by Hybrid Technology Application
}

\author{
Maharani Dian Permanasari, Dwinita Larasati \& Dian Widiawati \\ Magister of Design Program, Faculty of Visual Art and Design, \\ Institute of Technology Bandung, Jalan Ganesha 10, Bandung 40132, Indonesia \\ E-mail: maharani.dianp@yahoo.com
}

\begin{abstract}
Banana bark is one of tropical indigenous natural resources that can be used as main material for many products. Being a fast-growing renewable material, it is durable and has natural patterns that people find visually attractive. Naturally, its textures and patterns are its main values; therefore it has the potential to be developed further. This research is needed to optimize the growth of small craft industries of banana bark, including the community where production activities take place, and also to provide information or reference of banana bark utilizations. Previous experiments conclude that banana bark has porous structure, high flexibility, relatively water-resistant due to its natural wax coating that resists water droplets, unless being washed down immensely. Also, due to its softwood- and paper-like properties, ithas many possibilities to be formed and processed into various functional products, mostly as craft products. In the subsequent study, the research about the utilization of banana bark in small industries starting from the harvesting system, handling problems in raw material supply, applying proper technology in improving the material's quality, improving the human-resource working culture by appropriate technologies, and also innovating the product's designs. The recommended designs can be implemented to improve the performance and qualities of banana bark products.
\end{abstract}

Keywords: applied technology; banana bark; renewable materials; design; sustainability.

\section{$1 \quad$ Introduction}

Environmental issues and their applications in design are increasing with terms like Eco-Design, Green Design, Sustainable Design, or Design and Sustainability. In Larasati [1], indications of movement known as Sustainable Design starts from the concept of the book "The Silent Spring" by Carson [2] where she gave images about birds that no longer sing since they become extinct due to overuse of the pesticides, and "The Waste Makers" by Packard [3], where Packard expressed that he was unsatisfied by designers' works that have been causing negative impacts to the environment, that later became a serious discussion responded by various countries in the world. This was marked by the holding of international conferences, Intergovernmental Panel on

Received July $2^{\text {nd }} 2012,1^{\text {st }}$ Revision February $4^{\text {th }}, 2013,2^{\text {nd }}$ Revision May $2^{\text {nd }}, 2014$, Accepted for publication May $13^{\text {th }}, 2014$.

Copyright (C 2014 Published by LPPM ITB, ISSN: 1978-3078, DOI: 10.5614/itbj.vad.2014.6.2.5 
Climate Change (IPCC), as the first scientific organization founded by two United Nations (UN) organizations, namely WMO (World Meteorological Organization) and UNEP (United Nations Environment Program) in 1988, with

issues on Climate Change and Sustainable Development. The process of applying the sustainable development concept is then translated into products with aspects of sustainability in many countries, including in Indonesia as an agricultural country with numerous natural resources.

Indonesia has various natural materials that drive the growth of small craft industries with eco-friendly concept. Being a potential material, banana bark as the waste produced by banana plantations is still marginalized and less popular compared to other materials, such as bamboo, rattan, and water hyacinth. Despite its abundant availability in Indonesia, banana bark utilization is still lacking in further development, hence the main motivation of this research. In previous study, Permanasari [4] explored the possibilities of designing products with banana bark as the main material in order to add values in local craftsmanship and it has become another factor to develop the material's potential further in the present research. Other factors underlying this study partly because of the increasing of global attention towards environmental issues, especially towards products made from natural materials, and mainly because of the aesthetic values and potentials of banana bark to be developed further. According to Woodward [5], there are six ways of seeing material culture namely materials as "objects", "commodities", "artifacts", "goods", "things" and "actants". Banana bark is one entity that can be considered as an "actant", a material that can act socially and affect other objects around it.

The present research reviews mainly about the three factors of study objectives, namely the utilization of banana bark as an "actant" in product design, the application of hybrid technologies in improving the quality of banana bark, and material handling problems in the supply of raw materials. This research is also conducted to optimize utilization of human resources through the application of appropriate technology, and to formulate innovation in banana bark product design to reach a wider market share.

\section{$2 \quad$ Materials and Method}

According to Alexander [6], human beings continue to experience the need to invest the world with metaphysical meaning and to experience solidarity with objects outside the self. That notion is the background of hybrid technology application in preparing process and product development in this research. Improvements in the processing of raw banana bark materials are performed with exploratory experimental applications methods. This study aims to optimize the potential of banana bark based on its characteristics. Banana bark 
has porous material and structured of fibers in honeycomb arrangements that gives advantage in flexibility and sound absorption. This research is conducted to develop banana bark into an acoustic component unit by hybrid technology application that is suitable for Indonesians craftsmen community. Acoustic testing method Japanese Industrial Standard (JIS) A1405 is conducted to determine the sound coefficient absorption of banana bark. As a new material for acoustic purpose, banana bark is tested by two samples categories, which are uncoated and coated with varnish. Acoustic testing results are as following:

Table 1 Coefficient sound absorption of banana bark [7].

\begin{tabular}{ccc}
\hline Frequency & $\begin{array}{c}\text { Sample 1 } \\
\text { (coated) }\end{array}$ & $\begin{array}{c}\text { Sample 2 } \\
\text { (uncoated) }\end{array}$ \\
\hline 100 & 0.259 & 0.282 \\
125 & 0.515 & 0.499 \\
160 & 0.213 & 0.207 \\
200 & 0.636 & 0.633 \\
250 & 0.106 & 0.099 \\
315 & 0.101 & 0.115 \\
400 & 0.121 & 0.130 \\
500 & 0.182 & 0.193 \\
630 & 0.174 & 0.254 \\
800 & 0.103 & 0.244 \\
1000 & 0.475 & 0.293 \\
1250 & 0.464 & 0.532 \\
1600 & 0.400 & 0.736 \\
2000 & 0.558 & 0.363 \\
2500 & 0.356 & 0.225 \\
3150 & 0.341 & 0.269 \\
4000 & 0.363 & 0.280 \\
\hline
\end{tabular}

Table 1 of test results obtained the effective absorption spread between 125-200 $\mathrm{Hz}$ and 1000-4000 Hz. The larger the coefficient absorption value, the greater the ability of the banana bark to absorb sound. Maximum sound absorption occurs at low frequencies (especially at $200 \mathrm{~Hz}$ ), decreased by middle frequencies, but increased and evenly distributed at high frequencies (1000$4000 \mathrm{~Hz})$.

\subsection{Banana Bark as Acoustic Absorber Material}

Physical characteristics, composition, texture, and the absorption coefficient of banana bark qualify as an acoustic material. Developments of banana bark as acoustic material units have other advantages mostly on visual appearance, ease of installation, durability, replacement and refurbished possibilities. But as a 
natural material, banana bark still has its own limits so it cannot be used in a room with high humidity, swimming pools, industrial projects, mechanical equipment rooms, workshop machinery, vehicle terminals, and other outdoor environments. Designations of acoustic materials made from banana bark are relatively small rooms with low frequency scale. Another important consideration is noise criterion/noise rating, applied based on International Standard Organization (ISO) in Doelle [8] about noise criterion (NC) that can be accepted by human's hearing. Doelle [8] also explains about the level background noises that are allowed according to the threshold of human hearing in different types of space allocation. The NC recommendations for spaces can be seen in Table 2, as follows:

Table 2 Recommendations of background noise criterion for spaces.

\begin{tabular}{cc}
\hline Room types & NC number \\
\hline Concert room & $15-20$ \\
Radio/ record room & $15-20$ \\
Opera house & 20 \\
Theater stage & $20-25$ \\
Music room & $20-25$ \\
TV Broadcast studio & $20-25$ \\
Executive office & $20-30$ \\
Classroom & 25 \\
Movie studio & 25 \\
Conference hall & $25-30$ \\
Church/other place of worship & $25-30$ \\
Court & $25-30$ \\
School auditorium & $25-35$ \\
Residential bedroom & $25-35$ \\
Hotel/ Motel & $25-35$ \\
Movie theater/ cinema & 30 \\
Hospital & 30 \\
Semi-private office & $30-35$ \\
Library & $30-35$ \\
Business office & $35-45$ \\
Restaurant & $35-50$ \\
Art studio & $40-45$ \\
Gymnasium & $45-50$ \\
Accounting/ clerk room & $45-50$ \\
Sport stadium & 50 \\
\hline Source: Background noise criteria recommended for space, [8]. & \\
&
\end{tabular}

Source: Background noise criteria recommended for space, [8].

Once the data in Table 1 is applied to the noise level data in Table 2, one of design development decision that suits the criteria is a modular acoustic unit designed for a home theater room in private residences. 


\subsection{Design Experiment}

Experiments performed are plaiting woven technique and arranging processed banana bark into acoustic material panels. Plaiting is the selected technique because it retains banana bark's porous characteristic in tight and textured plait patterns. Although the plaiting technique is unfamiliar to local craftsmen, it can be taught without any difficulty. The plaiting technique can be seen in Figure 1.

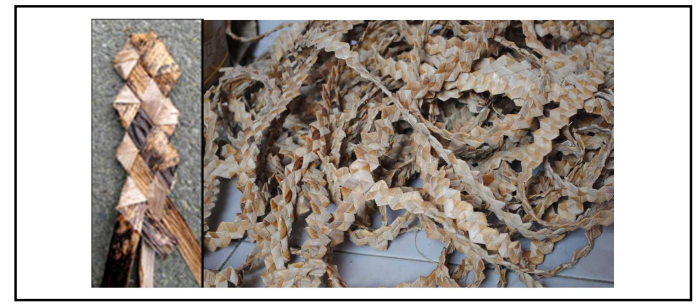

Figure 1 Banana bark plaiting techniques.

The plaiting lines are then arranged with various patterns before being applied to acoustic material frame units, as seen in Figure 2.

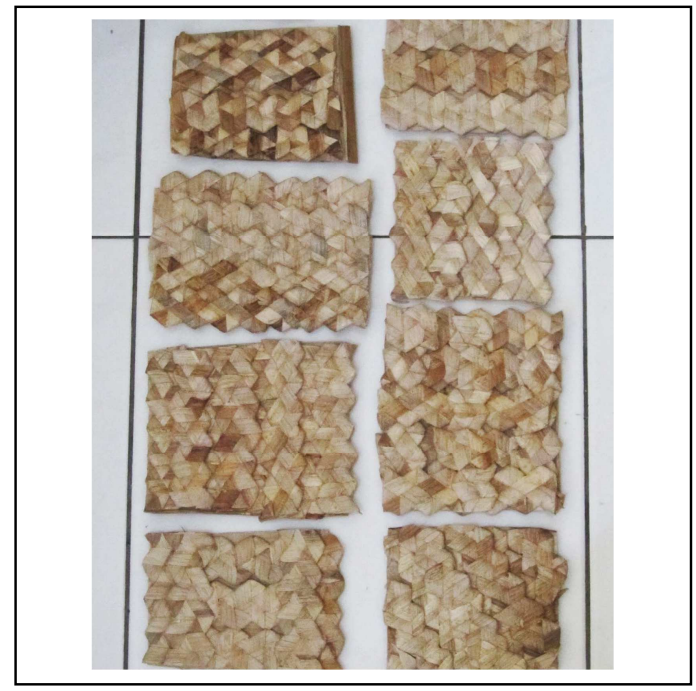

Figure 2 Banana bark plaiting patterns.

The plaiting patterns are then combined with light wood materials (e.g. pine wood, plywood) as the frames, as seen in Figure 3. The purpose of combining with light wood materials is to make it easier to attach in panel forms, which is developed in two forms: square $(30 \times 30 \mathrm{~cm})$ and rectangle $(15 \times 30 \mathrm{~cm})$. The 
measurement size is based on the regular size of building materials in the market, i.e. tiles, acoustic boards, etc.

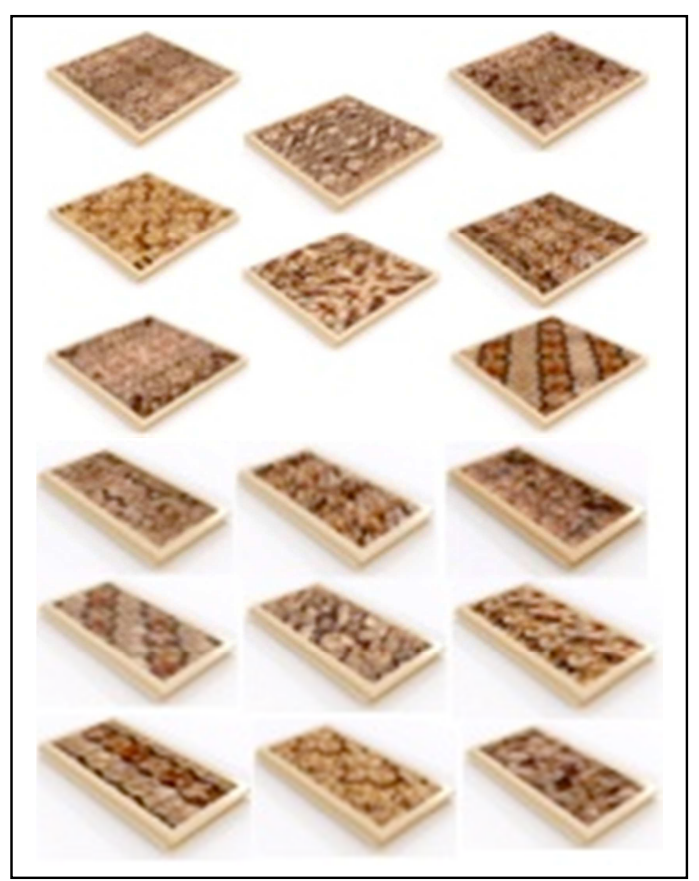

Figure 3 Acoustic material units in 3D rendering.

Details of the acoustic material units joint system can be viewed in Figure 4.

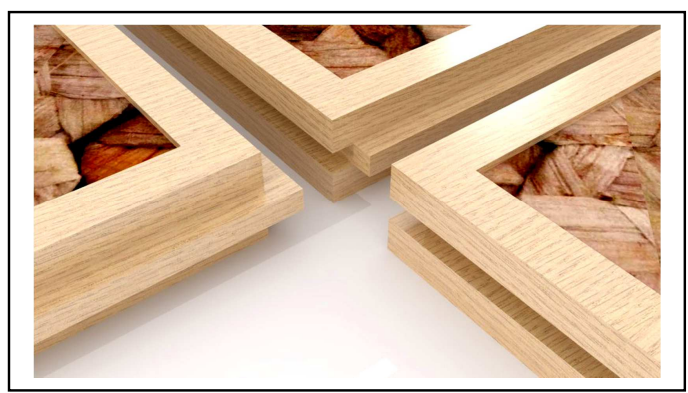

Figure 4 Acoustic material units in 3D rendering.

Compared to gypsum acoustic panels that are commercially available, banana bark acoustic panels are visually more attractive due to the possibilities of combinations on a wall; bear lighter weights, and yet possessing similar 
performance to conventional acoustic panels in absorbing sound. Banana bark acoustic panels are then applied to some parts of walls in a home-theater room that need sound absorber from the speakers. Design configuration examples of the banana bark acoustic panels in home theater rooms can be viewed in Figure 5 .

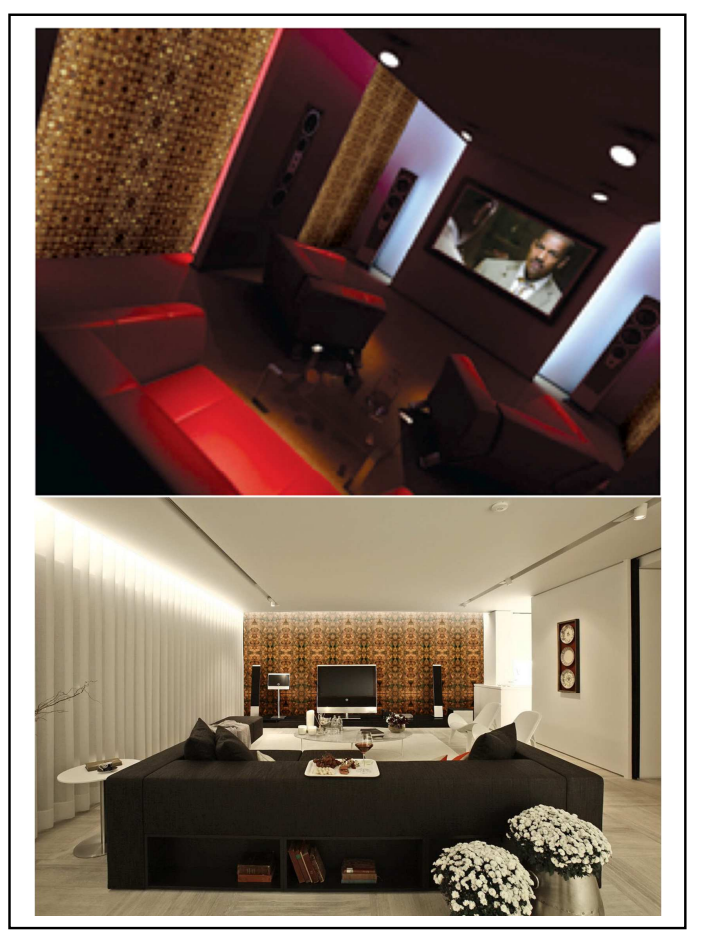

Figure 5 Design configurations in home theater rooms.

\section{Conclusions}

This research contains a series of mechanical process, design explorations and experiments in order to improve banana bark's potential into functional products. Verifications are needed to confirm this research's findings about innovation in acoustic material. Conclusions of research include banana bark's porous characteristics, which could potentially be developed as an acoustic material. Moreover, its natural textures provide an added value to the products. However, further experiments and explorations are still needed to enrich this research. 
Research on behavior and user interaction with the product is one separate study, since banana bark acoustic module configurations create patterns that will form certain visual impacts on the interior and will also affect the psychological conditions of people inside the room.

From the material perspective, it is also possible to combine banana bark with other natural materials, such as rubber, to optimize the sound absorption ability, with complementary research on the strength of banana fiber. Geographical conditions, as well as different weather conditions and soil contents where the banana trees grow, can make a difference in the fiber structure and the natural patterns of banana bark, so further research can be conducted in collaboration with various fields of scientific study, such as nanotechnology to improve the fiber's strength and structure and microbiology to control the growth of fungi that causes the emergence of patterns on the surface.

In addition to further development in individual research, banana bark acoustic units has a high potential for further development, due to the availability of raw material and the low production cost. Development of banana bark acoustic units in this research has become an invention of material use and production, which is commercially viable and can be realized in regions where banana plants originated. Therefore, its production technology, design patents and copyrights should be advantageous for the indigenous craftsmen who process the material.

\section{References}

[1] Larasati, D. 1999. Uncovering the Green Gold of Indonesia: A Design Research on Bamboo's Potential, Design Academy Eindhoven, Netherland.

[2] Carson, R. 1692. The Silent Spring, Houghton-Mifflin, Boston.

[3] Packard, V.O. 1960. The Waste Makers, David McKay, Co., Philadelphia.

[4] Permanasari, M.D. 2010. Eksplorasi Material Pelepah Pisang untuk Pengembangan Produk Industri Kerajinan, Program Studi Desain Produk, Fakultas Seni Rupa dan Desain, Institut Teknologi Bandung.

[5] Woodward, I. 2007. Understanding Material Culture, Sage Publications, Ltd., London.

[6] Alexander, Jeffrey. 2003. The Meanings of Social Life: A Cultural Sociology, Oxford University Press, New York.

[7] May 2012. Sound Absorption JIS A 1405 Results, Laboratory of Advanced Material for Building, PUSKIM Cileunyi, Bandung.

[8] Doelle, L.L. 1972. Environmental Acoustics, McGraw-Hill, Inc., New York. 